\title{
Descrição de Hephialtes mourei sp. nov. e notas em Hephialtes Thomson e Braderochus mundus (White) (Coleoptera, Cerambycidae, Prioninae)
}

\author{
Antonio Santos-Silva ${ }^{1}$
}

${ }^{1}$ Museu de Zoologia, Universidade de São Paulo. Caixa Postal 42494, 04218-970 São Paulo-SP, Brasil.

\begin{abstract}
Description of Hephialtes mourei sp. nov. and notes on Hephialtes Thomson and Braderochus mundus (White) (Coleoptera, Cerambycidae, Prioninae). Hephialtes mourei sp. nov. is described from Brazil (Minas Gerais, Rio de Janeiro, São Paulo and Paraná). Comments on the key to Braderochus Buquet and on the holotype of B. mundus (White, 1853) figured by Bleuzen (1994) are provided.
\end{abstract}

KEywords. Braderochus; Callipogonini; Hephialtes; Prionini; taxonomy.

Resumo. Hephialtes mourei sp. nov. é descrita do Brasil (Minas Gerais, Rio de Janeiro, São Paulo e Paraná). A chave para espécies de Braderochus e a ilustração do holótipo de B. mundus (White, 1853) fornecidas por Bleuzen (1994) são discutidas.

Palavras-Chave. Braderochus; Callipogonini; Hephialtes; Prionini; taxonomia.

Thomson (1864) criou Hephialtes para H. tricostatus proveniente do Brasil. No ano seguinte, THOMSON (1865) descreveu $H$. badium também do Brasil. LACORDAIRE (1869) sinonimizou $H$. tricostatus com H. sulcatus (Olivier, 1795) e considerou $H$. badium como espécie válida. GAHAN (1895) revalidou $H$. tricostatus e considerou Prionus sulcatus Olivier, 1795, como sinônimo de Orthosoma bruneum (Forster, 1771).

LAMEERE (1904) colocou Hephialtes na sinonímia de Stictosomus (Anacanthus) Audinet-Serville, 1832, e H. badium como sinônimo de $H$. tricostatus. LAMEERE (1912) sinonimizou H. tricostatus com Trachyderes ruber Thumberg, 1822, e manteve a espécie em Stictosomus (Anacanthus).

Monné (1995) escreveu: "Hephialtes sulcatus Lacordaire, 1869: 147 (Syntypes localities: Brasil and Cayenne)". No entanto, como foi visto acima, LACORDAIRE $(l . c$. ) estava se referindo à espécie de Olivier: "Prion. sulcatus, Oliv. Entom. IV, 66, p. 39, pl. 8, f. 27”. Dessa forma, os espécimes utilizados por LACORDAIRE $(l$. $c$.) para estudo da espécie, não são tipos, tendo ocorrido apenas um erro de identificação. TAVAKILIAN (1997) revalidou Hephialtes (Callipogonini) e manteve como única espécie H. ruber (Thumberg, 1822).

Durante o processo de identificação do material depositado no Museu de Zoologia, Universidade de São Paulo, São Paulo (MZSP) e Museu Nacional, Rio de Janeiro (MNRJ), foi encontrada uma nova espécie de Hephialtes Thomson, 1864, proveniente do Brasil. A nova espécie compartilha parte da distribuição geográfica de $H$. ruber, fato que, associado à semelhança morfológica entre as espécies, levou, inicialmente, à suposição de que se tratava de exemplares teratológicos. Um estudo mais acurado revelou que as modificações são constantes tanto nos machos quanto nas fêmeas, evidenciando uma nova espécie.

As constatações sobre Braderochus mundus (White, 1853) (Prionini), também surgiram durante o processo de identificação de material e julgo oportuno divulgá-las.

As abreviaturas citadas no texto correspondem às seguintes instituições: BMNH, The Natural History Museum, Londres; MNRJ, Museu Nacional, Universidade Federal do Rio de Janeiro, Rio de Janeiro; MZSP, Museu de Zoologia, Universidade de São Paulo, São Paulo.

\section{Hephialtes mourei sp. nov.}

(Figs. 1,2)

Macho (Fig. 1). Tegumento castanho. Cabeça grande e larga. Vértice com pontos grossos, abundantes e esparsos, maiores e mais cerrados em direção às áreas laterais. Fronte deprimida, com pontos esparsos e rasos (exceto nas áreas laterais onde os pontos são mais concentrados e profundos). Sutura coronal enegrecida entre os olhos, localizada em sulco moderadamente profundo, alargado em direção às suturas frontais. Ápice do labro projetado, arredondado ou subaguçado. Região posterior dos olhos com pontos grossos, profundos, em parte anastomosados. Genas pontuadas; ápice projetado e arredondado. Submento com pontos grossos, abundantes e bem marcados; pilosidade relativamente longa, mais abundante nas laterais. Mandíbulas com aproximadamente a metade do comprimento da cabeça; carena dorsal alta e larga; face látero-externa profundamente escavada no terço basal; escultura formada por pontos grossos, profundos e confluentes na área escavada da face láteroexterna e moderadamente fina e esparsa nas demais áreas; ápice largo, com o dente externo aguçado e o interno arredondado; face externa fracamente sinuosa junto à base do dente apical externo; margem interna com dois dentes grandes, arredondados: um próximo aos dentes apicais; o outro próximo à base. Antenas atingem o meio dos élitros; escapo não atinge a borda posterior do olho; antenômero III pouco mais longo 


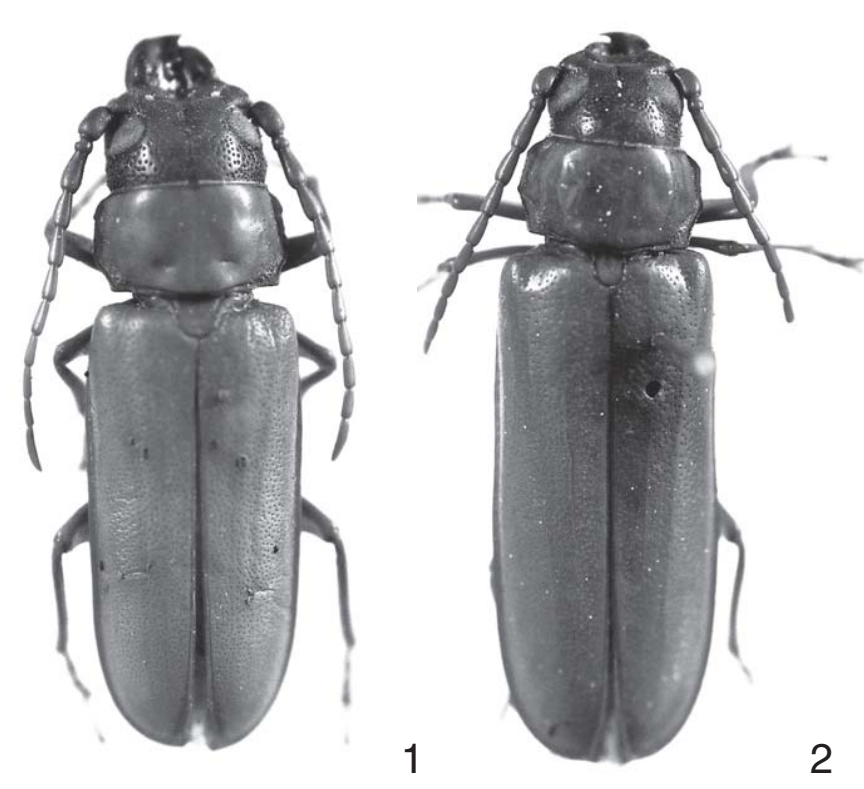

Figs. 1-2. Hephialtes mourei sp. nov., vista dorsal. 1, holótipo macho, comprimento $30,4 \mathrm{~mm} ; \mathbf{2}$, parátipo fêmea, comprimento $34,5 \mathrm{~mm}$.

do que o escapo e o antenômero IV.

Ângulos anteriores do pronoto arredondados; ângulos posteriores obtusos; margens laterais fracamente crenadas, subparalelas entre o ângulo anterior e o lateral e oblíqua desse ponto até o ângulo posterior; ângulos laterais pouco salientes, arredondados ou obtusos. Pronoto com pontuação esparsa, relativamente fina e rasa no disco e mais cerrada e grossa nas laterais. Prosterno com pontuação esparsa e pouco profunda. Élitros com pontuação abundante e bem marcada.

Fêmea (Fig. 2). Cabeça mais estreita e longa. Submento glabro ou com raros pêlos microscópicos. Mandíbulas semelhantes às dos machos. Antenas atingem o terço basal dos élitros.

Dimensões em mm (macho / fêmea). Comprimento total, 19,5-30,4 / 22,7-34,7; comprimento do protórax no centro, 3,34,8/3,5-4,7; maior largura do protórax, 5,0-8,3 / 6,1-8,4; largura umeral, 5,4-8,5 / 6,3-9,5; comprimento do élitro, 12,4-19,1 / 15,823,0 .

Material-tipo. Holótipo macho, BRASIL, Paraná: Arapoti (Lote 1040), II.1960, [sem nome do coletor], ex-coleção A. Maller (MNRJ). Parátipos. BRASIL, Minas Gerais: Lavras, fêmea, [sem data e nome do coletor], ex-coleção Campos Seabra; Manhumirim, fêmea, 30.III.1937, Zellibor \& Hauff col. (MNRJ); Viçosa, 1 macho e 1 fêmea, [sem data de coleta], A. M. Lobo col. (MZSP). Rio de Janeiro: Itatiaia (700 m), macho, 6.III.1927, J. F. Zikán col. (MZSP). São Paulo: Dois Córregos, fêmea, 20.II.1965, U. R. M. Souza col. (MZSP).

Discussão. Hephialtes mourei sp. nov. difere de H. ruber (ThUMBERG 1822): corpo mais robusto (Figs. 1, 2); mandíbulas com aproximadamente a metade do comprimento da cabeça; face látero-externa das mandíbulas com escavação basal maior e fracamente intumescida próximo ao meio; carena dorsal das mandíbulas bem marcada; pontuação mais fina e esparsa no pronoto e élitros; antenas atingem a metade dos élitros nos machos e o terço basal nas fêmeas; antenômero III pouco mais longo que o escapo e o antenômero IV; margens laterais do pronoto fracamente crenadas e com ângulos laterais pouco salientes. Em H. ruber (Figs. 3, 4): corpo mais esguio; mandíbulas, em geral, com aproximadamente um terço do comprimento da cabeça; face látero-externa das mandíbulas com escavação basal menor e fortemente intumescida próximo ao meio; carena dorsal baixa, larga e mal-delimitada (às vezes, como em $H$. mourei); pontuação mais grossa e densa no pronoto e élitros; antenas atingem o terço apical dos élitros nos machos e o meio dos élitros nas fêmeas; antenômero III com o dobro do comprimento do escapo e, no mínimo, um terço mais longo que o antenômero IV; margens laterais do pronoto mais nitidamente crenadas e com ângulos laterais salientes.

Etimologia. A espécie é dedicada a Jesus Santiago Moure (Departamento de Zoologia, Universidade Federal do Paraná), pelas inúmeras contribuições à entomologia brasileira, seja na formação de novas gerações de pesquisadores ou no inestimável subsídio propiciado por ele, ao fotografar grande quantidade de tipos depositados em instituições estrangeiras. Nesse último, este autor é eterno devedor por utilizar-se, com freqüência, desse precioso recurso.

\section{Braderochus mundus (White, 1853)}

(Fig. 5)

Aulacocerus mundus White, 1853: 13, pl. 1, fig. 2; Rojas, 1866: 238; Lacordaire, 1869: 86; Gemminger \& Harold, 1872: 2762 (cat.) .

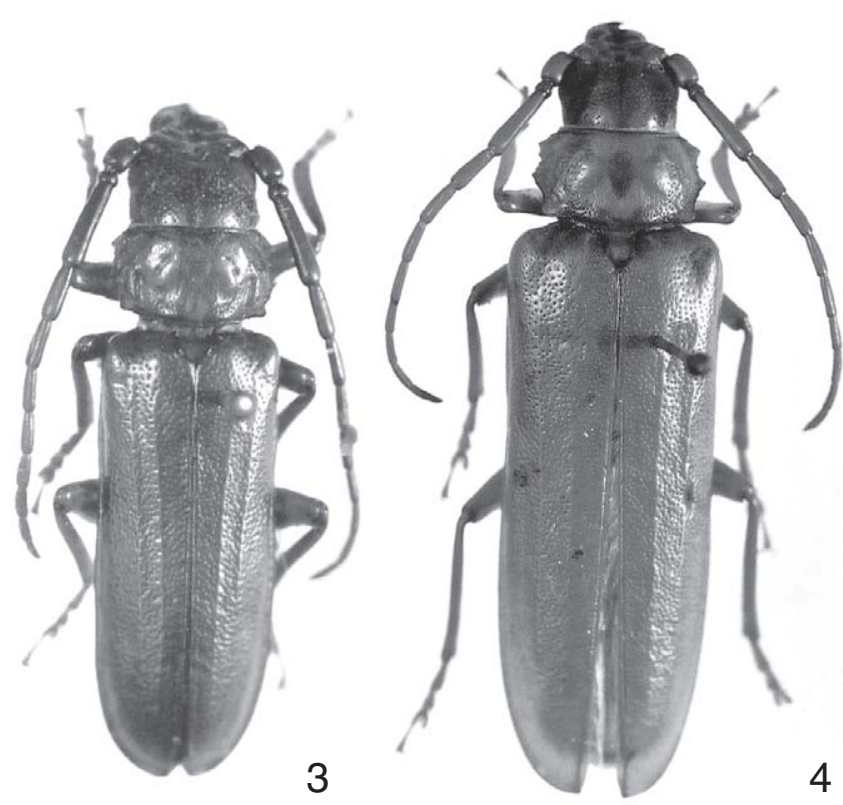

Figs. 3-4. Hephialtes ruber (Thumberg, 1822), vista dorsal. 3, macho, comprimento $28,2 \mathrm{~mm} ; \mathbf{4}$, fêmea, comprimento $27,0 \mathrm{~mm}$. 


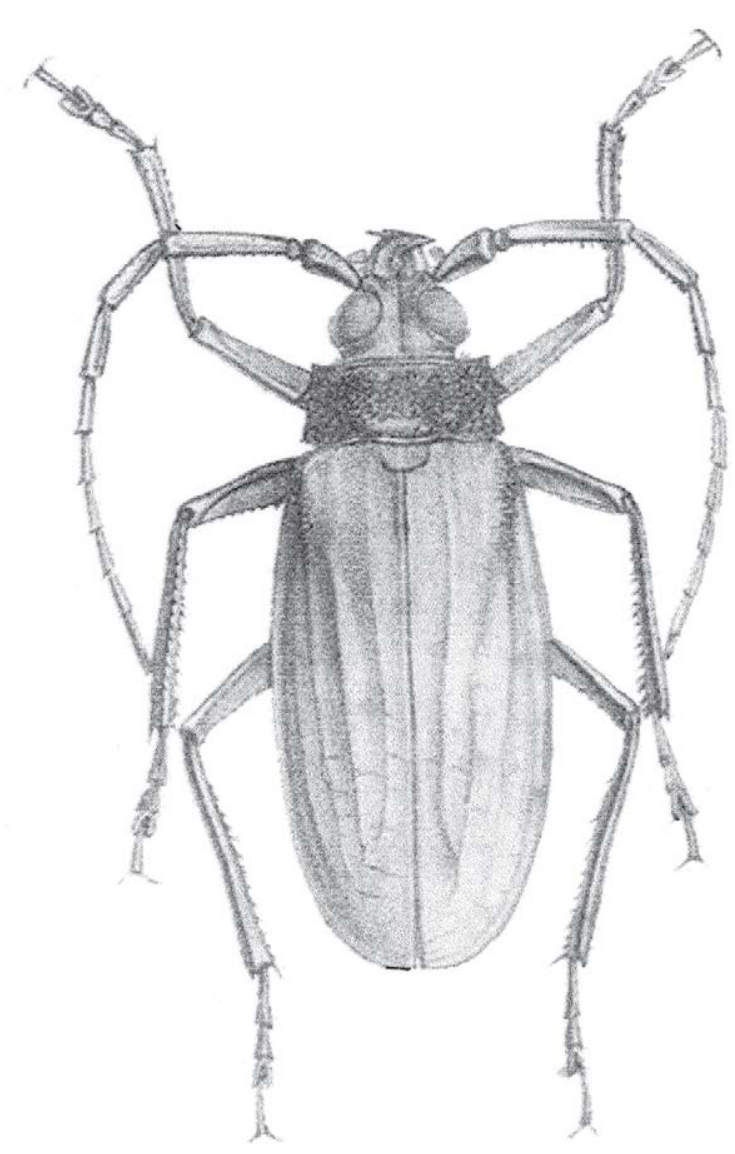

Fig. 5. Figura de White (1853) de Aulacocerus mundus (holótipo macho).

Titanus (Braderochus) mundus; Lameere, 1904: 319; 1913: 18 (cat.); 1919: 126; Rosales, 1966: 126, pl. 6, figs. 3, 4.

Titanus mundus; Blackwelder, 1946: 556 (cat.).

Braderochus mundus; Bleuzen, 1994: 50, pl. 15, figs. 1, 3, 4; Monné \& Giesbert, 1994: 13 (cat.); Monné, 1995: 63 (cat.).

BLEUZEN (1994) utilizou como primeiro dilema da chave para as espécies de Braderochus Buquet, 1852, a presença ou não de denticulação nos fêmures. Esse caráter, às vezes, é inútil, devido à sua variabilidade. B. mundus (White, 1853) insere-se no dilema (1), alternativa "présence de denticulations sur les fémures", na chave de BlEuZEN (l. c.). Rosales (1966) comentou sobre os machos dessa espécie: "La cara interna más o menos cóncava longitudinalmente, con los bordes presentando en forma aislada protuberancias agudas, de mayor o menor desarrollo, con cierta variación en los ejemplares; en algunos, estas protuberancias casi han desaparecido y sólo se ven vestigios de las mismas y en muy poca cantidad; en otros, son más notables y desarrolladas, incluso parecen pequeñas espinas". Rosales $(l . c$. ) nada comentou sobre o fêmur das fêmeas. Os profêmures de uma fêmea examinada (de porte grande) são praticamente inermes e os meso- e metafêmures apresentam apenas alguns espinhos curtos e esparsos.

BLeuzen $(l . c$. ) figurou, incorretamente, uma fêmea de $B$. mundus (BMNH) como holótipo. WHITE (1853) descreveu a espécie (Fig. 5) com base em um macho ("plate 1, fig. 2") com "length 25 lines" (= $53 \mathrm{~mm}$ ), o que também está em desacordo com a medida apresentada por BlEUZEN $(l . c$.$) : “(62 mm)".$

Material examinado. VENEZUELA. Aragua: Parque Nacional Henry Pittier (ex-Parque Nacional Rancho Grande), fêmea, 15.V.1950, Aresteguieta col.; (1100 m), macho, 20.IV.1955, F. F. Fernandez \& C. J. Rosales col. (MNRJ). Distrito Federal: Cerro del Naiguata, 1 macho e 1 fêmea, 26.VI.1938, [sem nome do coletor] (MZSP).

Agradecimentos. Ao Dr. Miguel A. Monné (MNRJ) pelo empréstimo de material para estudo e ao Dr. Ubirajara R. Martins (MZSP) pelo incentivo.

\section{REFERÊNCIAS}

Blackwelder, R. E. 1946. Checklist of the coleopterous insects of Mexico, Central America, the West Indies and South America. Part 4. Bulletin of the United States National Museum 185: 551763.

Bleuzen, P. 1994. Les Coléoptères du Monde. Prioninae I. Sciences Nat 21: 1-92.

Gahan C. J. 1895. On the longicorn Coleoptera of the West Indian Islands. The Transactions of the Entomological Society of London 1895: 79-140.

Gemminger, M. \& E. Harold. 1872. Catalogus Coleopterorum hucusque descriptorum synonymicus et systematicus. Monachii, 9: 2669-2988.

Lacordaire, J. T. 1869. Histoire Naturelle des Insectes. Genera des Coléoptères. Paris, Libr. Encycl. de Roret, 8: 1-552.

Lameere, A. 1904. Révision des prionides (Dixième mémoire - Titanines). Annales de la Sociétè Entomologique de Belgique 48: 309352.

Lameere, A. 1912. Révision des prionides (Vingt-deuxième mémoireAddenda et corrigenda). Mémoires de la Sociétè Entomologique de Belgique 21: 113-188.

Lameere, A. 1913. Coleopterorum Catalogus, pars 52, Cerambycidae. Prioninae. Berlin, W. Junk, 108 p.

Lameere, A. 1919. Genera Insectorum, Coleoptera, Fam. Cerambycidae, Subfam. Prioninae. Bruxelles, P. Wytsman, 172: 1189.

Monné, M. A. 1995. Catalogue of the Cerambycidae (Coleoptera) of the Western Hemisphere. Part XXII. São Paulo, Sociedade Brasileira de Entomologia, $115 \mathrm{p}$.

Monné, M. A. \& E. F. Giesbert. 1994. Checklist of the Cerambycidae and Disteniidae (Coleoptera) of the Western Hemisphere. Burbank, Wolfsgarden Books, xiv $+410 \mathrm{p}$.

Rojas, M. A. 1866. Catalogue des longicornes de la Province de Caracas, République de Venezuela, avec quelques observations sur leurs habitudes. Annales de la Sociétè Entomologique de France (4) 6: 236-248.

Rosales, C. J. 1966. Contribucion al conocimiento de los Prioninae (Coleoptera: Cerambycidae) de Venezuela. Revista de la Facultad de Agronomia de la Universidad Central de Venezuela 11: $1-237$.

TaVakilian, G. L. 1997. Nomenclatural changes, reinstatements, new combinations, and new synonymies among American Cerambycids (Coleoptera). Insecta Mundi 11(2): 129-139.

Thomson, J. 1864. Systema cerambycidarum ou exposé de tous les genres compris dans la famille des cérambycides et familles limitrophes. Mémoires de la Société Royale des Sciences de Liège 19: 1540 .

Thomson, J. 1865. Diagnoses d'espèces nouvelles qui seront décrites dans l'appendix du systema cerambycidarum. Mémoires de la 
Société Royale des Sciences de Liège 19: 541-578.

Thumberg, C. P. 1822. Trachyderes insecti genus ulterius examinatum et auctum sex novis speciebus. Mémoires de l'Académie Impériale des Sciences de Saint-Petersbourg 8: 303-307.

White, A. 1853. Catalogue of the coleopterous insects in the collection of the British Museum. Longicornia I. London, 7: 1-174.

Recebido em 24.VI.2003; aceito em 30.X.2003 